The management of volunteers - What can human resources do? $A$ review and research agenda

Kerstin Alfes

ESCP Europe Wirtschaftshochschule Berlin

Heubnerweg 8-10

14059 Berlin

Tel: +49(0)3032007 202

Email: kalfes@escpeurope.eu

(corresponding author)

Bethania Antunes

University of Greenwich, Business School

Old Royal Naval College

30 Park Row

London, SE10 9LS

Tel: +44 (0)20 83319021

Email: b.antunes@greenwich.ac.uk

Amanda D. Shantz

University of Greenwich, Business School

Old Royal Naval College

30 Park Row

London, SE10 9LS

Tel: +44 (0)20 83319000

Email: a.d.shantz@greenwich.ac.uk 
The management of volunteers - What can human resources do?

\title{
A review and research agenda
}

\begin{abstract}
There is an increasing interest from scholars and practitioners in understanding how nonprofit organizations can design and implement human resources (HR) practices to enhance desirable volunteer attitudes and behaviors. This paper presents a comprehensive overview of existing studies on the relationship between HR practices and volunteering outcomes. We use the ability-motivation-opportunity model (AMO) as a guiding framework to systematically integrate current knowledge on this topic. We identify gaps in existing research and offer detailed suggestions on how scholars can further enhance knowledge on how HR practices can lead to beneficial outcomes for both volunteers and non-profit organizations.
\end{abstract}

Keywords: HR practices, AMO model, volunteering, non-profit organizations, review 


\section{The management of volunteers - What can human resources do?}

\section{A review and research agenda}

\section{Introduction}

Volunteers make up a key component of the human resources (HR) of non-profit organizations today. With governments around the world cutting costs and reducing public spending, non-profit organizations now face mounting pressures to implement modern HR management practices not only with regards to their paid staff, but also in the management of their volunteers (e.g., Cuskelly, Taylor, Hoye, \& Darcy, 2006). Volunteers are often said to be the backbone of non-profit organizations, and although they tend to perform their duties out of care and concern for the beneficiaries of the non-profit organization, HR likely has a key role to play in facilitating their engagement, commitment and performance. Whereas non-profit organizations have, in the past, focused on advancing and implementing their vision for the future, they are beginning to acknowledge the importance of implementing a more professional approach to the management of volunteers in order to realize that vision.

The increasing emphasis on the professional management of volunteers in practice is paralleled by a growing body of research that suggests that HR practices have the potential to influence important volunteer outcomes. Much of this research implies that HR practices that have been developed in the paid context are transferable to those in the unpaid context; for instance, research has revealed the potential for HR practices to positively impact volunteers' satisfaction with their role (Fallon \& Rice, 2015), commitment to the organization (Newton, Becker, \& Bell, 2014), and their intent to remain volunteers (Millette \& Gagné, 2008).

Notwithstanding, there is reason to believe that there are unique differences between volunteers and paid staff. Unlike paid employees, volunteers do not receive monetary compensation for their work and consequently, non-profit organizations lack the formal reward and power structures to influence volunteer behavior. Hence, non-profit organizations 
rely on the 'rewarding experience of volunteering' to enhance the motivation of volunteers. Whereas paid employees are embedded in the organization's hierarchy with policies and procedures, volunteers benefit from greater independence in how their work is carried out. Although some non-profits also provide role descriptions for volunteers, the majority of volunteers are flexible in how they interpret their role. Further, paid versus unpaid staff often bring with them different values, attitudes and motivations. Research has demonstrated that regardless of holding the same job role, volunteers were more motivated by social interaction with others and by the opportunity to contribute towards achieving the non-profit's mission (Pearce, 1983). They also differed with regards to the intrinsic needs that were most relevant in influencing their attitudes and behaviors (Boezeman \& Ellemers, 2009).

While HR practices have the potential to positively influence the volunteer experience, the differences between volunteers and paid staff make it unlikely that HR practices designed and implemented in a paid context can be readily transferred to volunteers. A comprehensive review of studies exploring the relationship between HR practices and volunteer outcomes is therefore timely as it helps to understand the specific challenges and research gaps associated with HR in the volunteering context, and contributes to our knowledge in a number of ways.

First, research on the effect of HR practices on individual and organizational outcomes is fragmented and disjointed. Researchers from disciplines such as human resource management (e.g., Saksida, Alfes, \& Shantz, 2016), organizational behavior (e.g., Boezeman \& Ellemers, 2009), sociology (e.g., Wilson, 2000) and non-profit management (e.g., Vantilborgh et al., 2012) have carried out studies on HR and volunteering, with little integration between these parallel streams of research.

Second, there is a lack of conceptual framing and theoretical anchoring that might help us to understand the potential for HR practices to attract, engage, and retain volunteers. Although there are pockets of theory building on the influence of HR practices in the non- 
profit sector (e.g., Millette \& Gagné, 2008; Saksida et al., 2016; Wilson, 2012), current knowledge needs to be developed further in order to paint an up-to-date picture of research in this area.

Third, the majority of research to date has explored how individual HR practices such as recruitment (e.g., Bennett \& Kottasz, 2001), learning and development (e.g., Newton et al., 2014), or job design (e.g., Neufeind, Güntert, \& Wehner, 2013) influence volunteer outcomes without questioning whether HR practices may exert a synergistic impact on volunteers. Indeed, HR practices can act as bundles that are interconnected and therefore mutually reinforce each other (MacDuffie, 1995). A review paper is a step toward this end, as it enables researchers to view the constellation of prior research through an HR-focused organizing lens.

We chose to use the ability-motivation-opportunity (AMO) model as an organizing framework to summarize the current state of research on HR and volunteering and outline connections that exist between the variety of different studies on this topic. The AMO model proposes that organizations are best served by an HR system that attends to employees' ability (A) to carry out role requirements (i.e. recruitment, selection and training), their motivation (M) to engage in discretionary effort (i.e. formal and informal rewards), and by creating opportunities (O) for employees to contribute (i.e. job design, teamwork, and positive social interactions at work) (Lepak, Liao, Chung, \& Harden, 2006; Purcell, Kinnie, Hutchinson, Rayton, \& Swart, 2003). The AMO model has been widely used to explain the relationship between $\mathrm{HR}$ and performance (Jiang, Lepak, Hu, \& Baer, 2012), with researchers paying specific attention to the processes through which HR practices exert their influence. Since its inception, several authors have used the AMO model to observe employees' attitudes and behaviors as a result of applied HR practices (Kehoe \& Wright, 2013; Liao, Toya, Lepak, \& Hong, 2009). The AMO model provides a useful way of 
categorizing HR practices according to the mechanisms they induce in employees, and has been applied across a variety of different settings. Because of its universal nature, we suggest that the $\mathrm{AMO}$ is an appropriate framework to categorize existing research on $\mathrm{HR}$ in a volunteering context, and we will provide a deeper reflection on the usefulness of the AMO model as part of our synthesis.

\section{Identification of Studies}

The first criterion for inclusion in our review is that papers must focus on the management of volunteers in non-profit organizations. Volunteering is a specific form of helping activity. As suggested by Penner (2002, p. 448), it is defined “... as long-term, planned, prosocial behaviors that benefit strangers and occur within an organizational setting." This definition includes several noteworthy components. First, volunteering relates to planned activities (Rodell, Breitsohl, Schröder, \& Keating, 2016; Wilson, 2000), as opposed to spontaneous helping (e.g., helping a survivor of a car accident). Second, volunteering suggests that individuals regularly invest some time and effort by engaging in prosocial behaviors (Wilson, 2000). This is in contrast to other types of helping behaviors such as onetime helping (e.g., selling cakes at the $25^{\text {th }}$ anniversary celebration of the local football club). Third, volunteering takes place within an organizational context in that individuals carry out their volunteering activities within a formal context (Rodell et al., 2016). This differentiates volunteering from informal helping (e.g., helping an elderly neighbor with shopping) or private helping (e.g., caring for an elderly family member).

To collect studies to inform this review, we undertook a scientific database search using a series of keywords in order to develop a database of previously published research. The search was limited to scholarly articles and focused on studies which explored the impact of HR practices on attitudinal, behavioral intentions and behavioral outcomes. Although strategic HR scholars have increasingly explored the relationship between HR practices and 
well-being outcomes (Shantz, Arevshatian, Alfes, \& Bailey, 2016; Van De Voorde, Paauwe, \& Van Veldhoven, 2012) and volunteering enhances individual well-being (e.g., Alfes, Shantz, \& Bailey, 2016) we purposefully did not include studies on well-being. The databases covered in this search included Business Source Premier, JSTOR, Emerald, Sage, and Science Direct; journal-specific searches were undertaken with a number of selected journals including Human Resource Management, Human Resource Management Journal, and International Journal of Human Resource Management. From this list, we removed articles that focused on corporate volunteering, as the primary emphasis in those studies is not on non-profit organizations. We also omitted articles that focused on HR practices in a nonprofit context that were designed to benefit only paid employees or the public (i.e. training programs) and those few studies which adopted a purely macro-level perspective, where HR practices and volunteer outcomes where rated by one representative of the non-profit organization. Additionally, we did not include studies that described an HR practice that is directed toward volunteers but did not include information on volunteers' responses to it, or their behaviors associated with it.

Before reviewing the remaining articles, the research team developed an organizing framework that showed a list of HR practices which previous studies had classified as A, M or O-enhancing practices (e.g., Gardner, Wright, \& Moynihan, 2011; Jiang et al., 2012; Subramony, 2009). Two of the researchers subsequently categorized the HR practices described in each article according to this list as A, M, or O-enhancing practices. The results were compared and discrepancies were discussed among the research team. Studies which examined HR practices that fitted into more than one of the three categories were discussed in each of the relevant sections. In doing so, the AMO model provides a comprehensive perspective to organize the research literature on the influence of HR practices on outcomes of interest to both volunteers and non-profit organizations. 


\section{The AMO Model}

The following section presents the results of our literature review. In each section we present the studies that focused on HR practices belonging to the three different dimensions. We have included an overview of the articles and our categorizations in Table 1.

(INSERT TABLE 1 AROUND HERE)

\section{Ability-Enhancing HR Practices}

HR practices that enhance volunteers' ability are those that provide volunteers with the necessary competencies or skills to successfully complete tasks. Ability-enhancing HR practices include recruitment, selection, training, and development; they enable non-profit organizations to ensure that volunteers have the requisite knowledge, skills and abilities to support the organization's mission in line with its values and culture (Rogers, Jiang, Rogers, \& Intindola, 2016).

The recruitment and selection of volunteers enables non-profits to meet one of their main challenges - identifying the people who are most likely to volunteer for a specific cause, attracting them, and keeping them loyal (Randle \& Dolnicar, 2012). The aim of recruitment is to attract a small number of suitable applicants quickly and inexpensively, and it typically involves drafting and publicizing advertisements via common media outlets such as local newspapers, specialist publications, websites dedicated to promoting volunteering, and inviting current volunteers to invite friends, family and colleagues to volunteer (Broadbridge \& Horne, 1996; Whithear, 1999).

Although recruitment looks very much the same in non-profits as it does in for-profit firms, selection, on the other hand, is quite different in the non-profit sector. Wilson and Pimm (1996) stated that selection of paid staff involves selecting one applicant above at least 
one other, whereas with voluntary posts, selection is a question of whether a volunteer fits into the structure and is able to carry out the work involved. As a result, the selection process tends to be less structured in the non-profit sector. Another differentiating factor is that selection methods may, in some cases, act as a deterrent to recruits because of the nature of volunteering. Potential volunteers may find it presumptuous of non-profit organizations to question them when they are freely offering their time and skills (Wilson \& Pimm, 1996). Notwithstanding, some traditional selection tools are often used, including application forms, reference checks, and interviews, albeit with far less frequency than in the for-profit sector (Lynch \& Smith, 2009).

The recruitment and selection of volunteers is of paramount importance, given the increasingly episodic nature of volunteer participation (Snyder \& Omoto, 2008). Non-profit organizations that could once rely on a steady, loyal team of volunteers are challenged by a consistent need to recruit new individuals to their volunteer ranks. Indeed, volunteers themselves lament that recruitment and selection are the biggest challenges facing non-profit organizations today (Rogers, Rogers, \& Boyd, 2013). Our review of the literature shows that research has tended to focus on these ability-enhancing practices from, what we call, a motives-based, matching values, or loyalty perspective.

The motives-based perspective implies that in order to effectively recruit volunteers, it is important to understand potential volunteers' motives for volunteering in the first place. An understanding of what drives individuals to volunteer is important, as it allows non-profit organizations to target their recruitment activities to the profile, motives, and preferences of potential volunteers. Clary and Snyder (1999) pointed out that persuasive messages motivate people to initiate volunteering activities if such messages are tailored to the specific motivations important to the recipients of the messages. 
Although several inventories to assess volunteering motivations have been developed (e.g., Clary et al., 1998; Omoto \& Snyder, 1995; Reeder, Davison, Gipson, \& HessonMcInnis, 2001), the most well-known framework for assessing volunteer motives is the Volunteer Functions Inventory (VFI), developed by Clary et al. (1998). They differentiated among six motives for volunteering: Values - need to act in an altruistic way and help others; Understanding - need to have new learning experiences and the opportunity to practice new knowledge, skills and abilities; Social - need to be with friends or engage in an activity that others consider important; Career - need to build career-related skills and abilities which may serve to enhance one's career; Protective - need to reduce feelings of guilt over being more fortunate than others; and Enhancement - need for personal growth and development. Individuals may decide to volunteer for several motives and these motives may also change over time (Okun \& Schultz, 2003; Omoto, Snyder, \& Martino, 2000).

The value motive has received the most research attention. It is common to most existing inventories to assess volunteer motives, and it is not only endorsed as a valid motive by most volunteers, it is often regarded by them as the most important motive (Allison, Okun, \& Dutridge, 2002; Chacon, Perez, Flores, \& Vecina, 2011; Omoto \& Snyder, 1995). This body of research shows the benefits for non-profit organizations whose volunteers are motivated by this motive; they attend their shifts more regularly (Harrison, 1995; Penner \& Finkelstein, 1998), engage in more volunteer activities (Finkelstein \& Brannick, 2007; Plummer et al., 2008), provide more help to beneficiaries (Clary \& Orenstein, 1991), are more engaged in their volunteer tasks (Shantz, Saksida, \& Alfes, 2014), and devote more time to volunteer work (e.g., Allison et al., 2002; Finkelstein, 2008; Greenslade \& White, 2005; Okun, 1994).

Although there is very little research that has directly examined the link between recruitment for this motive (or others), most researchers who study volunteer motives recommend that non-profit organizations should design recruitment advertisements that tap 
into the value motive to attract and select a wide range of individuals. In one of the few studies to actually test this hypothesis, Bennett and Kottasz (2001) manipulated recruitment advertisements to be either egoistically versus altruistically (i.e. value motive) focused. They found that less altruistically inclined people responded more positively to recruitment advertisements which emphasized material and emotional benefits of volunteering; individuals with high altruism were more attracted by the altruistic recruitment messages. Although this study is laudable, it is limited in that they examined only two motives, and the study suffers from methodological limitations. A more rigorous methodology would be the use of the experimental method. Furthermore, research is also relatively silent on how to design recruitment advertisements based on motives for volunteering or other characteristics, such as age (Lancee \& Radl, 2014; Okun \& Schultz, 2003; Sundeen, Raskoff, \& Garcia, 2007).

The second approach, the matching approach, focuses on the match between volunteers' motives and the volunteering environment. Clary and Snyder (1999) suggested that doing so encourages sustained participation over time, and volunteers whose motivations are fulfilled by the context are more satisfied. In support of this, Okun and Schultz (2003) focused on the relationship between volunteer motives and volunteer age using a sample of 523 volunteers from an international housing and homelessness organization. They found that as volunteers age, they become more motivated to volunteer for social reasons, and less for career and understanding reasons. Although they suggested that recruitment advertisements should match the age profile of volunteers, this was not tested in their study.

Other research from this perspective does not define the specific motive to volunteer, but instead examines person-organization value fit, or the extent to which a volunteer perceives that his or her values are congruent with the values of the organization, regardless of what the values are. Newton and Mazur (2016) examined the relationship between person-organization 
values fit and work attitudes among both volunteers and paid employees of a non-profit organization in Australia. Their analyses revealed that for paid employees, the relationship between value congruence and positive work attitudes was positive, and the relationship was explained by the importance that employees attribute to the same values of the organization. Volunteers, on the other hand, sustained positive work attitudes regardless of their value congruence, "except where person values are in excess of organization values" (2016, p. 19). Hence, organizations that recruit and select volunteers who believe that their own values are stronger than the organization's values are likely to have volunteers with poorer attitudes toward their volunteer tasks. Although their research hints that matching values with the recruitment message might positively influence recruitment outcomes, the direct link is untested in their research. There is only one study, to our knowledge, that has directly tested this proposition. Using an experimental methodology, Clary, Snyder, Ridge, Miene and Haugen (1994) found that participants responded more favorably to matched, versus mismatched messages.

Three questions arise from the recommendation to match volunteers' characteristics to recruitment messages. The first is whether embedding multiple motives (rather than fewer) within recruitment messages will lead to better outcomes (Hager \& Brudney, 2011). A second question is whether emphasizing the value motive is sufficient. Although research states that the value motive tends to be most salient, not all volunteers are primarily motivated by it (e.g., Coyne \& Coyne, 2001), and instead, it might be worthwhile for organizations to develop a "recruitment niche" (mapping the profile of "ideal" volunteers) (King \& Lindsay, 1999; King, 1999) and tailoring messages that resonate with the niche. A third question is whether emphasizing some motives (i.e. career or self-protective) may have a detrimental impact on volunteering outcomes (see Dwyer, Bono, Snyder, Nov, \& Berson, 2013; Stukas, Hoye, Nicholson, Brown, \& Aisbett, 2016a; Stukas, Snyder, \& Clary, 2016b). 
The third perspective is what we call the loyalty approach. The underlying premise is that recruitment campaigns for non-profit organizations must carefully consider what or who to emphasize in terms of loyalty. For instance, non-profit organizations can emphasize the organizational mission and values, or specific programs or activities that volunteers carry out. A study of 652 volunteers of a non-profit organization showed that volunteers are more attached to their specific program, than to the non-profit organization as a whole (Hustinx \& Handy, 2009). Although untested, the authors claim that their results might have important implications for recruitment and selection strategies in large non-profit organizations with multiple locations and programs. In particular, they recommended that organizations should use specific information and characteristics of programs to match volunteers to specific programs rather than using the overarching mission of the organization (Hustinx \& Handy, 2009). Another choice is to emphasize the organization versus the people who work within the non-profit organization; Lee and Olshfski (2002) found that volunteer firefighters were more committed to their organization, whereas paid firefighters were more committed to their supervisors. Extrapolating from these findings, they asserted that paid staff might be more responsive to recruitment messages at the individual level, whereas emphasizing the organization's mission and values ignites volunteers' interest.

Relative to recruitment practices, there is far less research on the selection of volunteers. However, from what little research there is, it appears that selection may be an important step in ensuring high performance and retention of volunteers. For instance, Hager and Brudney (2011) found that screening and matching volunteers to appropriate assignments was positively related to volunteer retention across charities in the US. However, Lynch and Smith (2009) found that a lack of formal guidelines meant supervisors of a UK charity generally conducted the entire selection procedure without specialist HR advice, which led to informalities and subsequent inconsistencies in how selection processes were carried out. 
This finding is consistent with qualitative research of sports clubs in Switzerland which casts doubt that there is always a strategic orientation taken to recruitment and selection (Schlesinger, Klenk, \& Nagel, 2015). A strategic, top-down orientation to recruitment and selection may not be necessary in all situations. O'Toole and Grey (2016) examined 'thick volunteering" at the Royal National Institute of Lifeboat Institution and found recruitment, selection and training practices were informal yet highly rigorous, which then created even more motivation to volunteer, solidarity among the volunteers themselves, and a stronger sense of identity with the organization.

Volunteers can only perform their tasks effectively if they possess the necessary knowledge and skills. In this context, another important ability-enhancing practice in the AMO framework is training and development. Continuous and systematic training allows volunteers to develop the necessary skills to perform their volunteer activities. Despite the importance of training for improving performance, very few studies have examined this relationship (see Grossman \& Furano, 1999).

Conversely, research on the relationship between training and commitment and/or retention is far richer. For instance, research shows that training facilitates the commitment and/or retention of volunteers of Australian rugby clubs (Cuskelly et al., 2006), Spanish social and ecological non-profit organizations (Hidalgo \& Moreno, 2009), a wide range of Australian non-profits (Newton et al., 2014), bereavement volunteer programs in the US (Grossman \& Furano, 1999), human and environmental organizations in the US (Tang, Morrow-Howell, \& Hong, 2009), New Zealand sports volunteers (Allen \& Shaw, 2009), Irish elderly volunteers helping youth to read (Devaney et al., 2015), volunteers of a UK-based religious non-profit organization involved in international relief and development efforts (Saksida et al., 2016), a range of US (Hager \& Brudney, 2011; Jamison, 2003) and Spanish charities (Hidalgo \& Moreno, 2009), and volunteer emergency response workers in the UK 
(Waikayi, Fearon, Morris, \& McLaughlin, 2012).

Some attempts have been made to go beyond the direct relationship between training and development and outcomes of relevance to non-profit organizations by examining whether the value of training and development depends on a volunteer's motives for volunteering. For instance, Newton et al. (2014) found that volunteers with an understanding motive (the motivation to learn something new from volunteering) had higher levels of commitment when they were provided with learning and development opportunities, compared to volunteers with a weaker understanding motive. They also found that volunteers with strong career motives for volunteering reported significantly lower levels of intentions to stay; one explanation for this is that individuals with career motives, looking to gain skills, are likely to move to paid jobs once those skills are gained. Cuskelly et al. (2006) also examined the joint effect of training and motives; they found that intentions to remain volunteering for the nonprofit organization are only moderately affected by the value motive; training and development play a far stronger role than the value motive in influencing volunteer retention.

Other research has tried to unearth why training and development leads to higher retention. Saksida et al. (2016) examined the extent to which the provision of training and support from paid staff led to organizational commitment. They argued that when volunteers have high role mastery, competence and confidence in their role, they are more likely to contribute and internalize the organization's mission and form an attachment to it. The study revealed that training facilitated role mastery and consequently fulfilment of the volunteers' role. Other research has identified the mediator as culture change. In a description of a training program for a women's oriented non-profit organization (Dress for Success), the trainer, Groff (2006) discussed how diversity training led to a culture shift within the nonprofit organization, which was beneficial to both volunteers and the non-profit organization. This resonates with the findings of a study carried out in Australia by Costa et al. (2006) who 
found that the more that volunteers felt that they were able to share their experiences and opinions during training, the greater their sense of community whilst volunteering.

Although the bulk of research shows that training has positive attitudinal effects, there is less information on the extent to which training assists volunteers in performing well in their tasks. An additional limitation to the current body of research is on the content of training. Vantilborgh et al. (2012) reported that volunteers distinguished between induction training and specific workshops for experienced volunteers, and that a lack of either was demotivating. Moreover, research has all but ignored the possibility that an increase in training may create an unnecessary burden on non-profit administration, especially in a context in which volunteering is becoming increasingly episodic. This potential "dark side" to increasing levels of training may cause prospective volunteers to find training as an unnecessary waste of resources, or presumptuous on the part of non-profit organizations to require completion of training in order to undertake volunteer activities. For instance, Hartenian (2007) noted that some volunteers complained that the non-profit organization provided too much training, and concluded that training is not a worthwhile investment, especially considering that volunteers can easily discontinue their service.

\section{Motivation-Enhancing HR Practices}

The issue of motivation is fundamental to the AMO model and to HR research in general. One enduring topic in motivation is the distinction between intrinsically and extrinsically motivated behaviors (Deci, 1971; Deci \& Ryan, 2000). Intrinsic motivation refers to actions undertaken because they are inherently interesting and/or satisfying. The object therefore, resides in the behavior itself, and engaging in the behavior is enjoyable and can be characterized as a form of self-expression (Amabile, 1993). Conversely, extrinsically motivated behaviors are those that are performed to obtain a separable outcome. The activity 
is engaged with in order to gain a particular reward that holds some instrumental value (Ryan \& Deci, 2000).

Our review of the literature identifies a number of ways that research has investigated intrinsic rewards. Some studies report on the enjoyment volunteers gain from participating in the volunteer activity itself (e.g., Allen \& Shaw, 2009), but most of the research in this area emphasizes the meaningfulness that volunteers glean from understanding how their efforts make a difference to others. For instance, when volunteers fulfil their need to help others, they spend more time volunteering (Finkelstein, 2008) and report lower turnover intentions (Valéau, Mignonac, Vandenberghe, \& Gatignou Turnau, 2013). These studies suggest that the perception of making a difference is a rewarding experience for volunteers. Overall, one of the strongest rewards resulting from volunteering is a feeling of being able to help others, which leads to feelings of personal fulfilment and satisfaction (Stukas et al., 2016b). Although this research has taken the field a long way in understanding the intrinsic motivations of volunteers, the bulk of research has focused on just a few intrinsic motivators (e.g., generativity, self-transcendence values, universalism, benevolence, principle-ism, etc., see Stukas et al., 2016b for a review) and has failed to distinguish whether the meaningfulness gained from volunteering is focused on the work itself (i.e. volunteer engagement with tasks) or the belief that they make an impact on the beneficiaries of their activities.

Aside from intrinsic rewards, research has also examined the influence of extrinsic rewards on volunteer motivation. Although it may seem at first glance counterintuitive that volunteering can be an extrinsically motivated behavior, more than half of Clary et al.'s (1998) functional motives are extrinsic (Finkelstein, 2008) and there is a growing body of research which shows that volunteering can be an extrinsically motivated behavior. For instance, Nichols and Ralston (2012), in a qualitative study in the UK, identified personal 
status and identity, being provided with structured time, sharing experiences outside the family, dedicating time for a higher purpose and enforcing regular activity as important rewards that volunteers receive.

Vantilborgh et al. (2012) found that volunteers in Belgium value a number of extrinsic rewards, including recognition such as "thank-you events" and opportunities for social interaction so as to create a positive atmosphere where volunteers can develop friendships with others.

Likewise, Fallon and Rice (2015) found extrinsic rewards to be important. They compared paid employees and volunteers in an emergency services organization in Australia and found that support and recognition was a stronger predictor of job satisfaction and intention to stay for volunteers, relative to paid employees. They argued that support and recognition from the volunteer supervisor reflects the 'symbolic payment' that volunteers receive for their engagement in tasks, and although untested, they suggested that it may encourage them to remain in the organization more so than paid staff.

A number of studies corroborate this claim. Indeed, personal and public recognition of volunteering has been empirically linked to positive outcomes for the volunteer and nonprofit organization among older adult volunteers in human services organizations (Tang et al., 2009), top internet sites' contributors, but not lower-level contributors (Restivo \& van de Rijt, 2014), and a range of non-profits in the art, environment, community, welfare, health, youth, emergency services, religion and other sectors (Stirling, Kilpatrick, \& Orpin, 2011). In addition to the recognition of their contributions, research has also found that event volunteers in the UK are motivated by the quality of interpersonal relationships and clear communication of what is expected of them (Nichols \& Ojala, 2009).

Further studies focused on the reward preferences of volunteers in non-profit organizations. Phillips and Phillips (2010), for instance, examined which rewards were 
considered most desirable among volunteers in a US charity. The authors divided potential rewards for volunteers into two groups, tangible and intangible rewards. Intangible rewards such as feelings of satisfaction and ability to improve the community, had higher ratings than any of the tangible rewards. Among the tangible rewards however, a thank you note, a free cookie and opportunity to meet new people outscored other incentives with a financial value, such as movie tickets or a free meal. The results suggest that although volunteers do not generally work in the hope of receiving a valuable or costly benefit, they do display preferences among the various rewards available. In another study the authors (Phillips \& Phillips, 2011) argued that volunteers were motivated by a mix of altruistic and more selfserving motives. They suggested that individually-tailored rewards were more efficient than generic ones and concluded that non-profit organizations should avoid treating volunteers as a homogeneous group.

Whereas some research has shown positive outcomes of extrinsic motivators, other research has revealed that some extrinsic motivators can backfire. For instance, one study examined students' motivation to volunteer as mentors. Students exposed to an advertisement promising a small monetary reward were less likely to volunteer as peer mentors than those exposed to an advertisement promising no reward (Anghelcev \& Eighmey, 2013). Tang et al. (2009) found that the use of stipends to motivate low-income older volunteers was negatively associated with volunteer retention.

However, other research shows that providing tangible extrinsic motivators such as stipends may not always lead to negative outcomes. For instance, Cnaan and Cascio (1998) found that volunteers in a human services organization in the US dedicated more volunteering hours when provided with free medical services and free meals. Similarly, Stirling et al. (2011) found that not paying volunteers out of pocket expenses for meals, gas or transport was negatively associated with volunteer retention. Carpenter and Myers (2010) 
found that firefighters who were provided with a small stipend had increasing call response (higher performance), however, for firefighters who were concerned with their personal image, this effect had a zero net effect, suggesting that monetary rewards can discourage prosocial behavior among those who care about being perceived as altruistic by others. Hunter and Ross (2013) examined a government-initiated program in South Africa that includes stipend-paid volunteering. Although the volunteers' initial motivations were extrinsic, later their volunteerism was sustained by intrinsic motivations. Questions, however, remain regarding whether such government policy is a "euphemism for low-paid work."

Despite the general consensus that intrinsic rewards play a central role in motivating volunteers, this review highlights a range of extrinsic rewards used to motivate volunteers. Interestingly, whereas some research has presented evidence that certain extrinsic rewards lead to positive outcomes, other research shows just the opposite. This points to the important role of moderators in understanding the link between rewards and volunteer outcomes under what conditions do extrinsic motivators lead to desirable outcomes? Research on HR in the non-profit sector has also ignored the reality that volunteers are motivated by a complex mix of extrinsic and intrinsic rewards (Bruno \& Fiorillo, 2012). An exception is a study by Fiorillo (2011) who found that monetary rewards positively influenced the decision to volunteer, and importantly, extrinsic rewards did not crowd out intrinsic motivation but instead, those who were most likely to volunteer were both intrinsically and extrinsically motivated. Notwithstanding these important results, it is unclear from current research how non-profit organizations can strike the appropriate balance to stimulate volunteers to perform their tasks effectively and remain long-term in the organization. 


\section{Opportunity-Enhancing HR Practices}

Even if individuals have the ability and are motivated to perform their tasks, organizations still need to provide them with suitable opportunities to use their skills and fulfil their motivations if they want to sustain volunteer engagement (Lepak et al., 2006). In this context, opportunity refers to a volunteering environment that empowers volunteers and provides the necessary support and avenues for individual expression (Boxall \& Purcell, 2008).

Opportunity-enhancing practices play a specific role in the volunteering context. Compared to paid staff, volunteers are more motivated by social interactions with others and by an opportunity to contribute towards achieving the non-profit's mission (Pearce, 1983). Opportunity-enhancing practices tap into those motivations and therefore have the potential to foster a stronger identification between volunteers, their work, and the organization.

Paid staff and volunteers also differ in the extent to which their work is structured, as volunteers benefit from, and search for greater independence and flexibility in carrying out their roles. Opportunity-enhancing HR practices have the potential to increase volunteers' feelings of competence and enable them to take ownership of the tasks they are assigned to, thereby triggering positive volunteer reactions.

Our literature review has shown that in a volunteering context, studies have explored how opportunity-enhancing HR practices can be implemented with regards to three HR practices in particular: the tasks volunteers carry out, the support they are given in their immediate volunteering environment, and the involvement of volunteers in the non-profit organization.

Research on task features typically rely on the job characteristics model (Fried \& Ferris, 1987; Hackman \& Oldham, 1975; Morgeson \& Humphrey, 2006), which is based on the assumption that enriched jobs - ones that contain high levels of skill variety, task identity, 
task significance, autonomy and feedback - provide volunteers with opportunities to use their skills and motivation because they create space that enables performance. Although the job characteristics model has been extensively applied in workplaces with paid staff, only a handful of studies, to our knowledge, has examined job design in the context of volunteers.

Dailey's (1986) study was one of the first to examine the impact of job characteristics individually on the organizational commitment of volunteers, demonstrating that autonomy and feedback were specifically relevant in influencing volunteer political campaign workers' level of commitment. Schroer and Hertel (2009) examined the effect of job design on volunteers engaged in an unpaid German Wikipedia project. They found that job characteristics influenced volunteers' satisfaction and time spent volunteering, the latter effect being partially mediated by intrinsic motivation. Among the job characteristics, they found that autonomy, task significance and skill variety contributed most strongly to task performance.

Millette and Gagné (2008) examined the impact of an index of enriching job characteristics (the Motivation Potential Score) on satisfaction, intention to leave, and supervisory-rated task performance of volunteers in Canada. They found that volunteers with enriched roles were more satisfied with the work that they carried out and had higher levels of supervisory-rated performance. There was no significant relationship between job design and turnover intentions. In contrast, a study by Hidalgo and Moreno (2009) showed a positive relationship between positive job characteristics (a combination of eight dimensions including autonomy, task variety and significance) and intention to remain. A potential moderator was identified by Neufeind et al. (2013). Using a sample of 280 volunteers of sports events in Switzerland, they found that perceptions of job enrichment were positively related to satisfaction and higher intention to continue to volunteer in the future; however, the effect of job characteristics depend on the type of volunteering. Episodic volunteers benefited 
most from high task identity, but not autonomy in their intentions to volunteer at a similar event again, whereas for long-term volunteers, significant tasks were most motivational and increased their intention to volunteer for an organization in the future.

While the previous studies explored all five core job characteristics (Hackman \& Oldham, 1975), other studies used a subset of job characteristics or amended the dimensions that were part of the original job characteristics model. For example, McCormick and Donohue (2016) demonstrated that job role (a combination of four job characteristics) was positively related to affective commitment. In contrast, Bennett and Barkensjo (2005) did not find a significant relationship between job characteristics (autonomy, teamwork and supervisory support) and organizational commitment among volunteers offering assistance to people experiencing social problems in the UK. They did find, however, a positive relationship between supervisory support and volunteers' satisfaction with their role. Similarly, Pundt, Wöhrmann, Deller and Shultz (2015) found a positive relationship between autonomy, but not feedback from the job and work satisfaction amongst senior expert service volunteers in Germany, while Nencini, Romaioli and Meneghini's (2016) study revealed no significant effect of job characteristics (autonomy, task significance, consciousness of outcomes) on volunteers' motivation and satisfaction amongst volunteers in Italy.

A range of studies have taken a more focused approach. Rather than examining multiple job characteristics together, they explored the effect of single job characteristics on volunteer outcomes. Four studies showed that autonomy is positively related to the number of hours dedicated to volunteer work in an animal shelter in the US (Gagné, 2003), satisfaction and intent to volunteer again of sport event volunteers in Switzerland (Güntert, Neufeind, \& Wehner, 2015) and motivation and satisfaction of elderly volunteers in schools across Europe and the US (Oostlander, Güntert, \& Wehner, 2014). Moreover, in one of the few qualitative studies on job design in a volunteer context, sport event volunteers in New Zealand 
emphasized the importance of autonomy in their engagement with their volunteering activities. The volunteers had opportunities for input and choice and some degree of flexibility in the structure of their tasks. For example, each volunteer was asked to indicate which jobs they were interested in doing, and this sent a message to the volunteers that their skills were valued, they were being deployed effectively, and their input was valued (Allen \& Shaw, 2009)

Theory has begun to incorporate additional facets of job design outside of the classic five job characteristics. Arguably most germane to the non-profit context is the study of relational aspects of job design. The relational architecture of jobs refers to the properties of work that influence employees' opportunities to connect with others, including other employees and customers, for instance, and in the case of volunteering, those who benefit from the volunteering activities (Grant, 2007). Omoto, Snyder and Martino (2000) showed that the closeness of the relationship between volunteers and the beneficiaries of their services was strongly related to volunteers' satisfaction and commitment. Galindo-Kuhn and Guzley (2002) identified participation efficacy (volunteers' feelings that their participation will benefit someone) as a strong predictor of intent to remain volunteering. Alfes, Shantz and Saksida (2015) showed that the relational architecture of volunteer roles in an international development organization in the UK increased volunteers' intention to remain volunteering in the organization and was positively associated with the time dedicated to volunteering work. They concluded that the way volunteer roles are relationally designed provides opportunities for volunteers to witness the positive impact of their work and consequently spend more time and energy in their tasks.

Overall, these studies show some support for a positive relationship between job characteristics and desirable outcomes, however they fail to provide consistent evidence with regards to which dimensions are most relevant in a volunteering context. A potential 
explanation is that studies have been carried out in different types of non-profit organizations and countries using a different set of job dimensions which makes it difficult to compare and generalize findings. Moreover, studies have not answered the question of whether, in a volunteering context, jobs are designed by the non-profit organization, or instead, by the volunteers themselves. Volunteering provides ample opportunities for crafting jobs such that they fit the volunteer's preferences (Wrzesniewski \& Dutton, 2001) and might require future studies to adopt a more active view on the role of volunteers in designing their work environment.

The second way that HR can provide opportunity is through providing support to volunteers. This research shows that teamwork and social interactions strengthen the cohesion among volunteers, thereby fostering a positive volunteering climate and inducing volunteers to use their skills and motivations to help the non-profit organization achieve its strategic objectives. The role of teamwork in providing opportunity for volunteers was emphasized by Valeau, Willems and Parak (2016); using multilevel analysis of 207 Australian volunteer and paid firefighters nested within 51 non-profit organizations, they found that non-profit organizations that encouraged teamwork among paid and volunteer staff achieved higher ratings of perceived organizational effectiveness.

The importance of positive relationships with other volunteers for volunteers' satisfaction and continued service has also been emphasized in studies in the US (GalindoKuhn \& Guzley, 2002; Hager \& Brudney, 2011; Skoglund, 2006), Israel (Haski-Leventhal \& Bargal, 2008), and Italy (Zappa \& Zavarrone, 2010). Similarly, Hustinx's (2010) study among volunteers and ex-volunteers of Red Cross-Flanders showed that a negative atmosphere in the volunteer group led volunteers to quit their role. In contrast, Nencini et al. (2016) demonstrated that positive relationships with other volunteers influenced volunteers' satisfaction, but did not show a significant relationship with regards to quitting volunteering 
services. However, they found that having positive relationships with the board reduced volunteers' intention to leave.

The role of supportive work environments in providing volunteers with the opportunity to use their knowledge and skills and to fulfil their motivations has been highlighted in further studies. Specifically, research has shown that volunteers who forge meaningful relationships with other members of the non-profit organization, such as the supervisor, paid staff, or beneficiaries are more likely to show positive attitudes and remain volunteering among Spanish (Hidalgo \& Moreno, 2009), Belgian (Hustinx, 2010), Australian (Costa et al., 2006; Huynh, Metzer, \& Winefield, 2012; McCormick \& Donohue, 2016), Italian (Lo Presti, 2013), Scottish (Allen \& Bartle, 2014) and Irish volunteers (Devaney et al., 2015). Saksida et al. (2016) extended this work by showing that supportive relationships with staff members provided volunteers with a feeling of mastery over their roles, as volunteers felt guided and supported by others. This helped them to gain clarity on how they should carry out their roles. Consequently, they felt more competent and confident in carrying out their tasks effectively, and showed higher levels of commitment.

Allen and Shaw (2009) emphasized the importance of fostering a sense of relatedness in order to create a motivational climate among volunteers. They found that volunteers enjoyed the connections with other volunteers and the management team. They also valued managers who knew the names of each of the volunteers, helped out when needed, treated each person fairly, trusted the volunteers, and delivered supportive comments. This is supported by a study carried out by Yagi (2006) who examined the different leadership styles of two Indian literacy centres. In one village, there was only one coordinator who shouldered the entire responsibility of the centres, regardless of the number of coordinators who were supposed to help. In a second, the work of supervision was shared among a number of people, and the 
supervision was more frequent and regular. They found that volunteers were far more motivated in latter versus the former literacy centre.

Overall, our review provides substantial evidence to suggest that support is important in creating opportunities for volunteers to become embedded in the social structure of the nonprofit organization, thereby fostering positive volunteer attitudes and behaviors. However, our review also demonstrated some inconsistent findings with regards to the source of support (i.e. other volunteers, the supervisor, the organization) that is most relevant in creating a positive climate for volunteering. Moreover, studies did not provide much information with regards to the nature of support that was required. Arguably, having regular chats with co-volunteers versus receiving specific coaching sessions after emotionally difficult interactions with beneficiaries might trigger very different effects on volunteers.

Finally, the third way that organizations can provide opportunities is through volunteer involvement, or sharing information and giving them the opportunity to participate in decision-making. Implementing such practices shows that the non-profit cares about their volunteers and treats them with respect, which leads them to reciprocate through favorable attitudes and behaviors. Lo Presti' s (2013) study showed that volunteers who were informed about their organization and their volunteering role showed higher levels of commitment, satisfaction, and intention to remain. This result was confirmed by Bennett and Barkensjo (2005) whose study revealed that internal marketing techniques (including communication) were related to higher levels of commitment and satisfaction. Finally, a study by Waters and Bortree (2012) highlighted the different means of communication that were relevant in retaining male versus female volunteers. While social group inclusion was most strongly related to female volunteers' satisfaction, male volunteers' satisfaction and commitment was also influenced by inclusion in the organization's information network, and participation in decision making. 
Overall, our review shows consistent support for the assumption that involvement and participation of volunteers, as part of opportunity-enhancing practices, are important in fostering positive volunteering outcomes. However, studies do not differentiate between the levels of involvement that are necessary to trigger positive reactions from volunteers. While some studies suggest that information-oriented practices are already perceived positively, other studies focus on practices that enable a deeper involvement such as participation in decision-making, and with one exception (Waters \& Bortree, 2012), do not take volunteer or non-profit characteristics into account.

\section{The AMO Model in a volunteering context}

In presenting the findings from our review, we have relied on the AMO model as a categorizing framework to organize and describe studies on HR in the volunteering context. Our review of the current state of literature has demonstrated that non-profit organizations use ability-, motivation- and opportunity-enhancing practices to engage and retain their volunteers. However, while our review suggests that the AMO model can be applied to the volunteering context, doing so merits some reflection. First, while all three dimensions of the model are relevant for volunteers, the relative weighting of each dimension may be different compared to paid staff. Whereas ability, motivation and opportunity are similarly important to foster positive attitudes and behaviors in employees, ability-enhancing practices, specifically, recruitment and selection, are likely to be relatively more important for volunteers. This is because of the episodic nature of volunteering, where individuals dedicate shorter and more infrequent time spells to their volunteering activities (Snyder \& Omoto, 2008). Hence, practices that attract individuals to dedicate time to a specific non-profit organization are of utmost importance and can help the organization to substantially enlarge its volunteering pool. Second, the range of HR practices that HR managers can use for 
volunteers is somewhat limited compared to paid staff. For example, monetary rewards for volunteers are, in most cases, not applicable. Offering job security, one of the key motivationenhancing practices in a paid context, is difficult to translate to a volunteering context. Finally, research has demonstrated that a strong identification with the organizational values, mission and culture (Tidwell, 2005) is an important part of the volunteering experience, which leads to positive reactions from volunteers. The potential for HR practices to trigger sense-making processes is not taken into account in the AMO model in its current form, and future research could investigate whether the AMO model needs to be enriched by a fourth pathway to fully capture the different mechanisms induced by HR practices in a volunteering context.

\section{Human resource management and volunteering: Emerging issues and directions for}

\section{future research}

\section{Building a stronger theoretical framework for the effect of $H R$ on volunteers}

\section{Underpinning foundations of HR theory in volunteering}

Theory to understand the potential for HR practices to make an impact on attracting, engaging, and retaining volunteers remains in its infancy. Although non-profit researchers have been investigating the potential for $\mathrm{HR}$ practices to make an impact in non-profit organizations for some time (e.g., Fenwick, 2005), differences in values, mission, identity, social goals, outcomes, and ideological characteristics may compromise direct applications of HR research and theory from for-profit to non-profit organizations (Ridder \& McCandless, 2010). On the other hand, others suggest that there is much to be learned from HR scholarship, as large non-profit organizations often approach HR issues in much the same way as for-profit firms of comparable size (Lynch \& Smith, 2009). One way forward is to 
examine the extent to which current HR theories apply to a volunteering context. For instance, researchers could explore the extent to which a strong HR system (Bowen \& Ostroff, 2004) can create a volunteering culture in which individuals feel included in the organization and willing to reciprocate through dedicating more time to their services and showing higher levels of performance. Indeed, research has shown that the organizational context can serve as a "strong situation", thereby muting the relative effect of motivations on outcomes (Stukas, Worth, Clary, \& Snyder, 2009). Researchers might also gain inspiration from public management theories in their efforts to explain volunteering behaviors. This is because the motivation of public sector employees shares a conceptual overlap with volunteer motivations, as public sector employees are often motivated by the objective of giving back to society (Perry, 1996). Second, researchers are encouraged to develop frameworks that help to theoretically identify which HR practices, or combinations of HR practices, are relevant in shaping volunteer outcomes. Finally, scholars should aim to understand the design and content of HR practices, and their impact on volunteers. For instance, what recruitment methods are most effective for volunteers? Under what conditions do incentives such as stipends lead to beneficial outcomes? Which types of support are needed to integrate volunteers? Answering these questions is an important step towards understanding how nonprofit organizations can develop HR practices that foster volunteer retention and therefore helps them to carry out their services effectively. In summary, more research is needed which develops new theoretical approaches to the management of volunteers taking into account the specific characteristics of the volunteering workforce (Liao-Troth, 2001).

\section{Understanding the processes through which AMO practices influence volunteer outcomes}

The vast majority of studies included in our review have explored direct relationships between HR practices and volunteer outcomes. More research is needed to understand the mediating mechanisms through which the effects of HR practices unfold. Although our 
categorization of HR practices within the AMO model is consistent with prior theory and research (i.e., Jiang et al., 2012), it is possible that the same HR practice influences volunteer attitudes and behaviors via $a$ bility, motivation, and/or opportunity. For instance, research has shown that training has the potential to increase both volunteers' abilities, and it might also be considered a reward (motivation); likewise, teamwork can be considered a motivator and an opportunity. An examination of mediators will enable us to understand why HR practices exert favorable outcomes in a volunteering context.

We also encourage researchers to explore boundary conditions that strengthen or weaken the relationship between $\mathrm{HR}$ practices and volunteer outcomes. Boundary conditions at different levels are likely to moderate how HR practices exert their influence. At the organizational level, HR practices should have a stronger effect on volunteer outcomes when volunteers identify with the non-profit organization's mission and values. At the team level, the relationship that volunteers develop with their volunteer manager as well as the quality of the interactions between group members may moderate the relationship between HR practices and volunteer outcomes. Finally, individual and volunteering role characteristics likely influence the volunteers' responses to HR practices. Studies exploring how different factors interact with HR practices to influence outcomes of relevance will help us better understand when HR practices are effective.

\section{Including a broader range of outcome variables}

The majority of studies included in our review have explored how different types of HR practices influence volunteer attitudes such as satisfaction with their volunteering roles, commitment to their non-profit organization and intent to remain volunteering. The central proposition of the AMO model suggests, however, that HR practices designed to enhance the ability, motivation and opportunity of volunteers will ultimately increase individual performance and organizational outcomes (Jiang, Takeuchi, \& Lepak, 2013). Given the 
increasingly competitive environment for non-profit organizations, one of the key unanswered questions is the extent to which HR practices foster these outcomes in a volunteering context. We therefore encourage future research to explore the extent to which ability, motivation and opportunity-based HR practices enhance volunteers' performance in their role, the behaviors they demonstrate outside their role and the effectiveness of the nonprofit organization, for example, in raising funds or supporting beneficiaries. Doing so is important as improved volunteer performance implies that beneficiaries receive more or a better service, that more fund-raising takes place or that campaigning is more successful, thereby improving the performance of the organization and its ability to attract donors and additional volunteers.

\section{Putting volunteering into context}

The majority of research on volunteering has been carried out in single organizations, without considering the specific volunteering setting and without comparing how volunteering unfolds across different contexts. Few studies identify the organizational features of non-profits that impact upon which HR practices are used and the extent of their effectiveness in promoting valuable volunteer and organizational outcomes. Organizational size, for instance, is likely to be of importance (Hager \& Brudney, 2011); scholars (e.g., Lynch \& Smith, 2009) have suggested that the size of the organization is the main differentiator in formalization and adoption of HR practices in non-profits. Developing and implementing effective HR practices might be more relevant for a large-scale international NGO compared to a small local charity, as international NGOs are increasingly required to demonstrate that they use professional management practices to their stakeholders, including donors. Likewise, Marx (1999) stated that smaller non-profits have more difficulty recruiting volunteers, relative to larger more prestigious institutions possibly because of their brand, 
reach, and marketing. However, Hager and Brudney (2011) did not find that large organizations have a distinct advantage in attracting volunteers; smaller ones did just as well.

Another issue is the type of work that is carried out, or the purpose of the non-profit organization. Marx (1999, pp. 51-52) commented that volunteers may be more difficult to recruit when the beneficiaries "are primarily intravenous drug users rather than a class of suburban elementary school children." This sentiment was echoed by Leviton, Herrera, Pepper, Fishman and Racine (2006) who noted that social service agencies face problems in the recruitment of volunteers to service those with chronic illness. The type of work may also influence how jobs are designed, the extent to which it is possible to use teamwork, and the type of leadership style needed from paid staff. For instance, it may be that training is a stronger driver of volunteer performance in non-profit organizations operating in a health or human services context compared to non-profit organizations operating in a sports domain. Similarly, research suggests that the effectiveness of HR practices depends on whether volunteering takes place as part of a one-time event such as the Olympics, or is a long-term commitment of time (Neufeind et al., 2013) and the pattern of HRM practices used in nonprofits is dependent on the ratio of volunteers-paid staff (Guo, Brown, Ashcraft, Yoshioka, \& Dong, 2011). This led Hager and Brudney (2011) to conclude that non-profits must take their "nature" into account when developing HR strategies. Hence, it is important that researchers make purposeful decisions about the settings within which they collect their data and make this clear when presenting their research findings.

Another factor that may impact the use or effectiveness of HR practices is the extent to which volunteers are in direct-facing roles, whereby they interact directly with the beneficiaries of the non-profit organization, or in indirect-roles, whereby they work "behind the scenes" in roles such as fundraising, accounting, etc. Using a mixed-methods design of 30 volunteer agencies in the US, Hartenian (2007) found marked differences in the number of 
HR practices used to recruit, motivate and retain volunteers in direct versus indirect roles. For instance, fewer recruitment methods were used for those in direct roles, and more rewards were afforded to those in indirect roles. An additional factor that may influence the effectiveness or appropriateness of HR practices is the extent to which volunteers are willing to take on long versus short term assignments. O'Connor (1997) noted that charities are deliberately changing their recruitment procedures in recognition that short-term volunteers are more interested in the work itself and demand clearer job descriptions and training. Given the small scale of these research studies, more research is needed on this important topic, perhaps using HR architecture theory to inform it (Lepak \& Snell, 1999).

Finally, more research is needed to examine the influence of national contexts on how HR practices are designed and how they manifest themselves in volunteering outcomes. As highlighted in Table 1, the majority of volunteering research has been carried out in a Western context. More studies are needed to explore volunteering processes in non-Western countries to outline which HR practices are relevant in, for example, Asian and African countries. Moreover, we strongly encourage researchers to take a cross-cultural approach in exploring the relationship between HR practices and volunteer outcomes (Handy et al., 2010). Scholars have argued that HR practices are a reflection of the wider institutional environment in which organizations operate (Paauwe \& Boselie, 2003).

Similarly, researchers have argued that the importance of the non-profit sector, as well as the way volunteering is organized are an outcome of a country's historical routes and traditions. For example, Salamon, Sokolowski and Anheier (2000) differentiate between four models of third sector regime, characterized by high versus low government social welfare spending and small versus large non-profit sector size. The types of volunteering that have developed in a country as well as the importance of volunteering for a country's functioning differs between these models, and has implications for the types of volunteers that are 
attracted and how they are managed. For example, in liberal countries such as the US and the UK, characterized by limited government social welfare spending, volunteering is encouraged, and oftentimes focused on service delivery. In contrast, in social democratic countries such as Scandinavian countries, social welfare provision by the state is relatively large, and as a consequence, volunteering is focused on advocacy, recreational and hobby organizations (Anheier \& Salamon, 1999). Studies should therefore explore how historical routes, cultural values, macroeconomic conditions, the amount of financial compensation received through national governments, and the regulatory environment influence the development of HR practices and their impact on volunteers. Putting HR into context ensures that researchers move away from a "one size fits all" towards a more tailored approach which takes into account that the management practices developed for volunteers need to match the volunteering environment to be effective. While best practices can give a first hint at which HR tools are likely to make a difference, they need to be adapted to the specific setting in order to deliver their full potential.

\section{Striking a balance between management and flexibility}

Our review highlights that HR practices designed to enhance the ability, motivation and opportunities for participation can have a positive impact on volunteers' attitudes and behaviors, and help non-profit organizations manage their volunteer workforce more effectively. At the same time, creating a rigid work environment with too many formalized procedures may counterbalance volunteers' need for autonomy and self-fulfillment (Boezeman \& Ellemers, 2009), thereby reducing the positive effects of HR practices. Research has highlighted that volunteers are demotivated by bureaucratic, transactional approaches and this is particularly important in light of the current operating environment of non-profit organizations (Stirling et al., 2011). Pressures to promote management 
accountability have inundated the day-to-day management of non-profit organizations (Cunningham, 2010; Cunningham \& James, 2009), and therefore there is a need for studies exploring how HR practices can be designed to create a balance between management control and volunteer autonomy.

\section{Methodological issues}

\section{Multilevel Studies}

HR researchers have long pointed out that HR practices can be conceptualized at multiple levels (e.g., Paauwe, 2009; Wright \& Boswell, 2002). HR practices are developed by the HR department (intended HR practices), implemented by the volunteer manager and perceived by individual volunteers. The majority of studies to date have focused on volunteers' perceptions with regards to their organization's HR practices. More research is needed which takes into account how non-profit organizations develop HR practices for volunteers at a strategic level and explores the intentions behind those HR practices as well as any differences between intended practices and volunteer perceptions of these practices. Doing so is important, as identifying mechanisms (such as frequent communication or creating a strong culture) to reduce those inconsistencies will help non-profit organizations to manage their volunteers more effectively, and ensure that their strategic HR intentions are transmitted to their volunteer workforce.

\section{Longitudinal studies}

Cross-sectional studies do not enable researchers to draw conclusions with regard the causal order of variables. Studies exploring volunteers' responses to HR practices over multiple time points is needed to conclude with confidence, that HR practices influence volunteer outcomes and not the other way around. It could theoretically be possible that 
volunteers with high levels of commitment and job satisfaction experience positive emotions in their volunteering role, which in turn, leads them to assess the HR practices in their nonprofit organization positively.

\section{Measuring performance}

Few studies have included behavioral outcomes and those that do tend to measure hours spent volunteering as an outcome variable (Shantz et al., 2014). This leads to an important question related to the measurement of performance among volunteers. Conceptually, it is difficult to transfer performance dimensions used to measure the behavior of paid employees into a volunteering context (Motowildo, Borman, \& Schmit, 1997). For example, citizenship behaviors relate to activities that are not required as part of an employee's core tasks (Organ, 1997). Volunteering is, per definition, a form of helping activity and therefore related to citizenship behaviors, as all volunteers engage in activities that are done on a non-profit basis and not required by any organization. More research is needed to investigate the different performance dimensions of volunteering.

\section{Making a link to organizational performance outcomes}

The strategic human resource tradition of research explores the extent to which HR practices influence organizational outcomes. Similarly, an avenue that is worthy of additional research is whether non-profit organizations that deploy HR practices for their volunteers reap benefits by demonstrating greater organizational performance. More studies are needed to identify potential links between intended HR practices, and for example, a non-profit organization's ability to attract and secure funding from donors, the extent to which they are able to implement their mission and provide important services to their beneficiaries, and their reputation in the public, as mediated by volunteer attitudes and behaviors. 


\section{Conclusion}

This paper has provided an in-depth review of studies exploring the impact of HR practices on volunteering outcomes by integrating a burgeoning body of research which has explored this relationship. We have demonstrated that the AMO model is a suitable framework to categorize existing research. Our paper highlights that, despite the advances in our knowledge, more studies are needed to develop and test propositions regarding HR's impact in non-profit organizations via the professional management of their volunteers.

\section{References}

Alfes, K., Shantz, A., \& Bailey, C. (2016). Enhancing volunteer engagement to achieve desirable outcomes: What can non-profit employers do? VOLUNTAS: International Journal of Voluntary and Nonprofit Organizations, 27, 595-617. doi: 10.1007/s11266-015-9601-3

Alfes, K., Shantz, A., \& Saksida, T. (2015). Committed to whom? Unravelling how relational job design influences volunteers' turnover intentions and time spent volunteering. VOLUNTAS: International Journal of Voluntary and Nonprofit Organizations, 26, 2479-2499. doi: 10.1007/s11266-014-9526-2

Allen, J. B., \& Bartle, M. (2014). Sport event volunteers' engagement: Management matters. Managing Leisure, 19, 36-50. doi: 10.1080/13606719.2013.849502

Allen, J. B., \& Shaw, S. (2009). "Everyone rolls up their sleeves and mucks in": Exploring volunteers' motivation and experiences of the motivational climate of a sporting event. Sport Management Review, 12, 79-90. doi: http://dx.doi.org/10.1016/j.smr.2008.12.002

Allison, L. D., Okun, M. A., \& Dutridge, K. S. (2002). Assessing volunteer motives: A comparison of an open-ended probe and likert rating scales. Journal of Community \& Applied Social Psychology, 12, 243-255. doi: 10.1002/casp.677

Amabile, T. M. (1993). Motivational synergy: Toward new conceptualizations of intrinsic and extrinsic motivation in the workplace. Human Resource Management Review, 3, 185-201. doi: http://dx.doi.org/10.1016/1053-4822(93)90012-S

Anghelcev, G., \& Eighmey, J. (2013). The impact of extrinsic incentives on students' willingness to volunteer as peer mentors: Implications for advertising education. Journal of Advertising Education, 17, 5-16.

Anheier, H. K., \& Salamon, L. M. (1999). Volunteering in cross-national perspective: Initial comparisons. Law and Contemporary Problems, 62, 43-65.

Bennett, R., \& Barkensjo, A. (2005). Internal marketing, negative experiences, and volunteers'commitment to providing high-quality services in a uk helping and caring charitable organization. VOLUNTAS: International Journal of Voluntary and Nonprofit Organizations, 16, 251-274. doi: 10.1007/s11266-005-7724-0 
Bennett, R., \& Kottasz, R. (2001). Advertisement style and the recruitment of charity volunteers. Journal of Nonprofit \& Public Sector Marketing, 8, 45-63. doi: 10.1300/J054v08n02_05

Boezeman, E. J., \& Ellemers, N. (2009). Intrinsic need satisfaction and the job attitudes of volunteers versus employees working in a charitable volunteer organization. Journal of Occupational \& Organizational Psychology, 82, 897-914.

Bowen, D. E., \& Ostroff, C. (2004). Understanding hrm-firm performance linkages: The role of the "strength" of the hrm system. Academy of Management Review, 29, 203-221.

Boxall, P., \& Purcell, J. (2008). Strategy and human resource management (2 ed.). Basingstoke: Palgrave Macmillan.

Broadbridge, A., \& Horne, S. (1996). Volunteers in charity retailing: Recruitment and training. Nonprofit Management and Leadership, 6, 255-270. doi: $10.1002 / \mathrm{nml} .4130060305$

Bruno, B., \& Fiorillo, D. (2012). Why without pay? Intrinsic motivation in the unpaid labour supply. The Journal of Socio-Economics, 41, 659-669. doi: http://dx.doi.org/10.1016/j.socec.2012.05.020

Carpenter, J., \& Myers, C. K. (2010). Why volunteer? Evidence on the role of altruism, image, and incentives. Journal of Public Economics, 94, 911-920. doi: http://dx.doi.org/10.1016/j.jpubeco.2010.07.007

Chacon, F., Perez, T., Flores, J., \& Vecina, M. L. (2011). Motives for volunteering: Categorization of volunteers' motivations using open-ended questions. Psychology in Spain, 15, 48-56.

Clary, E. G., \& Orenstein, L. (1991). The amount and effectiveness of help: The relationship of motives and abilities to helping behavior. Personality and Social Psychology Bulletin, 17, 58-64. doi: 10.1177/0146167291171009

Clary, E. G., \& Snyder, M. (1999). The motivations to volunteer: Theoretical and practical considerations. Current Directions in Psychological Science, 8, 156-159.

Clary, E. G., Snyder, M., Ridge, R. D., Copeland, J., Stukas, A. A., Haugen, J., \& Miene, P. (1998). Understanding and assessing the motivations of volunteers: A functional approach. Journal of Personality and Social Psychology, 74, 1516-1530.

Clary, E. G., Snyder, M., Ridge, R. D., Miene, P. K., \& Haugen, J. A. (1994). Matching messages to motives in persuasion: A functional approach to promoting volunteerism. Journal of Applied Social Psychology, 24, 1129-1146. doi: 10.1111/j.15591816.1994.tb01548.x

Cnaan, R. A., \& Cascio, T. A. (1998). Performance and commitment: Issues in management of volunteers in human service organizations. Journal of Social Service Research, 24, 1-37.

Costa, C. A., Chalip, L., Green, B. C., \& Simes, C. (2006). Reconsidering the role of training in event volunteers' satisfaction. Sport Management Review, 9, 165-182.

Coyne, B. S., \& Coyne, E. J. (2001). Getting, keeping and caring for unpaid volunteers for professional golf tournament events. Human Resource Development International, 4, 199-216. doi: 10.1080/13678860121999

Cunningham, I. (2010). The hr function in purchaser-provider relationships: Insights from the uk voluntary sector. Human Resource Management Journal, 20, 189-205.

Cunningham, I., \& James, P. (2009). The outsourcing of social care in britain. Work, employment and society, 23, 363-375.

Cuskelly, G., Taylor, T., Hoye, R., \& Darcy, S. (2006). Volunteer management practices and volunteer retention: A human resource management approach. Sport Management Review, 9, 141-163. doi: http://dx.doi.org/10.1016/S1441-3523(06)70023-7 
Dailey, R. C. (1986). Understanding organizational commitment for volunteers: Empirical and managerial implications. Nonprofit and Voluntary Sector Quarterly, 15, 19-31. doi: $10.1177 / 089976408601500102$

Deci, E. L. (1971). Effects of externally mediated rewards on intrinsic motivation. Journal of Personality and Social Psychology, 18, 105-115. doi: 10.1037/h0030644

Deci, E. L., \& Ryan, R. M. (2000). The 'what' and 'why' of goal pursuits: Human needs and the self-determination of behavior. Psychological Inquiry, 11, 227-268.

Devaney, C., Kearns, N., Fives, A., Canavan, J., Lyons, R., \& Eaton, P. (2015). Recruiting and retaining older adult volunteers: Implications for practice. Journal of Nonprofit \& Public Sector Marketing, 27, 331-350. doi: 10.1080/10495142.2015.1015373

Dwyer, P. C., Bono, J. E., Snyder, M., Nov, O., \& Berson, Y. (2013). Sources of volunteer motivation: Transformational leadership and personal motives influence volunteer outcomes. Nonprofit Management and Leadership, 24, 171-205. doi: 10.1002/nml.21084

Fallon, B. J., \& Rice, S. M. (2015). Investment in staff development within an emergency services organization: Comparing furture intention of volunteers and paid employees. International Journal of Human Resource Management, 26, 485-500.

Fenwick, M. (2005). Extending strategic international human resource management research and pedagogy to the non-profit multinational. The International Journal of Human Resource Management, 16, 497-512. doi: 10.1080/09585190500051480

Finkelstein, M. (2008). Predictors of volunteer time: The changing contributions of motive fulfullment and role identity. Social Behavior and Personality, 36, 1353-1364.

Finkelstein, M. A., \& Brannick, M. (2007). Applying theories of institutional helping to informal volunteering: Motives, role identity, and prosocial personality. Social Behavior and Personality, 35, 101-114.

Fiorillo, D. (2011). Do monetary rewards crowd out the intrinsic motivation of volunteers? Some empirical evidence for italian volunteers. Annals of Public and Cooperative Economics, 82, 139-165. doi: 10.1111/j.1467-8292.2011.00434.x

Fried, Y., \& Ferris, G. R. (1987). The validity of the job characteristics model. A review and meta-analysis. Personnel Psychology, 40, 287-322. doi: 10.1111/j.17446570.1987.tb00605.x

Gagné, M. (2003). The role of autonomy support and autonomy orientation in prosocial behavior engagement. Motivation and Emotion, 27, 199-223. doi: 10.1023/A:1025007614869

Galindo-Kuhn, R., \& Guzley, R. M. (2002). The volunteer satisfaction index. Journal of Social Service Research, 28, 45-68. doi: 10.1300/J079v28n01_03

Gardner, T. M., Wright, P. M., \& Moynihan, L. M. (2011). The impact of motivation, empowerment, and skill-enhancing practices on aggregate voluntary turnover. The mediating effect of collective affective commitment. Personnel Psychology, 64, 315350. doi: 10.1111/j.1744-6570.2011.01212.x

Grant, A. M. (2007). Relational job design and the motivation to make a prosocial difference. Academy of Management Review, 32, 393-417. doi: 10.5465/AMR.2007.24351328

Greenslade, J. H., \& White, K. M. (2005). The prediction of above-average participation in volunteerism: A test of the theory of planned behavior and the volunteers functions inventory in older australian adults. Journal of Social Psychology, 145, 155-172. doi: 10.3200/socp.145.2.155-172

Groff, S. (2006). Exploring the value and impact of diversity training for a female-oriented nonprofit. Performance Improvement, 45, 30-34. doi: 10.1002/pfi.2006.4930450707

Grossman, J. B., \& Furano, K. (1999). Making the most of volunteers. Law and Contemporary Problems, 62, 199-218. 
Güntert, S. T., Neufeind, M., \& Wehner, T. (2015). Motives for event volunteering: Extending the functional approach. Nonprofit and Voluntary Sector Quarterly, 44, 686-707. doi: 10.1177/0899764014527797

Guo, C., Brown, W. A., Ashcraft, R. F., Yoshioka, C. F., \& Dong, H.-K. D. (2011). Strategic human resources management in nonprofit organizations. Review of Public Personnel Administration, 31, 248-269. doi: 10.1177/0734371x11402878

Hackman, J. R., \& Oldham, G. R. (1975). Development of the job diagnostic survey. Journal of Applied Psychology, 60, 159-170. doi: 10.1037/h0076546

Hager, M. A., \& Brudney, J. L. (2011). Problems recruiting volunteers: Nature versus nurture. Nonprofit Management and Leadership, 22, 137-157. doi: 10.1002/nml.20046

Handy, F., Cnaan, R. A., Hustinx, L., Kang, C., Brudney, J. L., Haski-Leventhal, D., . . . Zrinscak, S. (2010). A cross-cultural examination of student volunteering: Is it all about résumé building? Nonprofit and Voluntary Sector Quarterly, 39, 498-523. doi: $10.1177 / 0899764009344353$

Harrison, D. A. (1995). Volunteer motivation and attendance decisions: Competitive theory testing in multiple samples from a homeless shelter. Journal of Applied Psychology, 80, 371-385. doi: 10.1037/0021-9010.80.3.371

Hartenian, L. S. (2007). Nonprofit agency dependence on direct service and indirect support volunteers: An empirical investigation. Nonprofit Management and Leadership, 17, 319-334. doi: 10.1002/nml.152

Haski-Leventhal, D., \& Bargal, D. (2008). The volunteer stages and transitions model: Organizational socialization of volunteers. Human Relations, 61, 67-102. doi: $10.1177 / 0018726707085946$

Hidalgo, M. C., \& Moreno, P. (2009). Organizational socialization of volunteers: The effect on their intention to remain. Journal of Community Psychology, 37, 594-601. doi: $10.1002 /$ jcop. 20317

Hunter, K., \& Ross, E. (2013). Stipend-paid volunteers in south africa: A euphemism for lowpaid work? Development Southern Africa, 30, 743-759. doi: $10.1080 / 0376835 X .2013 .860014$

Hustinx, L. (2010). I quit, therefore i am? Volunteer turnover and the politcs of selfactualization. Nonprofit and Voluntary Sector Quarterly, 39, 236-255.

Hustinx, L., \& Handy, F. (2009). Where do i belong? Volunteer attachment in a complex organization. Administration in Social Work, 33, 201-220.

Huynh, J.-Y., Metzer, J., \& Winefield, A. (2012). Engaged or connected? A perspective of the motivational pathway of the job demands-resources model in volunteers working for nonprofit organizations. VOLUNTAS: International Journal of Voluntary and Nonprofit Organizations, 23, 870-898. doi: 10.1007/s11266-011-9233-1

Jamison, I. B. (2003). Turnover and retention among volunteers in human service agencies. Review of Public Personnel Administration, 23, 114-132. doi: 10.1177/0734371x03023002003

Jiang, K., Lepak, D. P., Hu, J., \& Baer, J. C. (2012). How does human resource management influence organizational outcomes? A meta-analytic investigation of mediating mechanisms. Academy of Management Journal, 55, 1264-1294. doi: 10.5465/amj.2011.0088

Jiang, K., Takeuchi, R., \& Lepak, D. P. (2013). Where do we go from here? New perspectives on the black box in strategic human resource management research. Journal of Management Studies, 50, 1448-1480. doi: 10.1111/joms. 12057

Kehoe, R. R., \& Wright, P. M. (2013). The impact of high-performance human resource practices on employees' attitudes and behaviors. Journal of Management, 39, 366-391. doi: 10.1177/0149206310365901 
King, G., \& Lindsay, N. (1999). Redefining the recruitment niche for the guide association in the united kingdom. Leisure Sciences, 21, 307-320. doi: 10.1080/014904099273020

King, G. N. L. (1999). Redefining the recruitment niche for the guide association in the united kingdom. Leisure Sciences, 21, 307-320. doi: 10.1080/014904099273020

Lancee, B., \& Radl, J. (2014). Volunteering over the life course. Social Forces, 93, 833-862. doi: $10.1093 / \mathrm{sf} / \mathrm{sou} 090$

Lee, S. H., \& Olshfski, D. (2002). Employee commitment and firefighters: It's my job. Public Administration Review, 62, 108-114. doi: 10.1111/1540-6210.62.s1.19

Lepak, D. P., Liao, H., Chung, Y., \& Harden, E. E. (2006). A conceptual review of human resource management systems in strategic human resource management research. Research in Personnel and Human Resource Management, 25, 217-271.

Lepak, D. P., \& Snell, S. A. (1999). The human resource architecture: Toward a theory of human capital allocation and development. Academy of Management Review, 24, 3148. doi: 10.5465/amr.1999.1580439

Leviton, L. C., Herrera, C., Pepper, S. K., Fishman, N., \& Racine, D. P. (2006). Faith in action: Capacity and sustainability of volunteer organizations. Evaluation and Program Planning, 29, 201-207. doi: http://dx.doi.org/10.1016/j.evalprogplan.2006.01.011

Liao-Troth, M. A. (2001). Attitude differences between paid workers and volunteers. Nonprofit Management and Leadership, 11, 423-442. doi: 10.1002/nml.11403

Liao, H., Toya, K., Lepak, D. P., \& Hong, Y. (2009). Do they see eye to eye? Management and employee perspectives of high-performance work systems and influence processes on service quality. Journal of Applied Psychology, 94, 371-391. doi: $10.1037 / \mathrm{a} 0013504$

Lo Presti, A. (2013). The interactive effects of job resources and motivations to volunteer among a sample of italian volunteers. VOLUNTAS: International Journal of Voluntary and Nonprofit Organizations, 24, 969-985. doi: 10.1007/s11266-012-92887

Lynch, S., \& Smith, K. (2009). The dilemma of judging unpaid workers. Personnel Review, 39, 80-95. doi: doi:10.1108/00483481011007878

MacDuffie, J. P. (1995). Human resource bundles and manufacturing performance. Organizational logic and flexible production systems in the world auto industry. Industrial \& Labor Relations Review, 48, 197-221.

Marx, J. D. (1999). Motivational characteristics associated with health and human service volunteers. Administration in Social Work, 23, 51-66. doi: 10.1300/J147v23n01_03

McCormick, L., \& Donohue, R. (2016). Antecedents of affective and normative commitment of organisational volunteers. The International Journal of Human Resource Management, 1-24. doi: 10.1080/09585192.2016.1166388

Millette, V., \& Gagné, M. (2008). Designing volunteers' tasks to maximize motivation, satisfaction and performance: The impact of job characteristics on volunteer engagement. Motivation and Emotion, 32, 11-22.

Morgeson, F. P., \& Humphrey, S. E. (2006). The work design questionnaire (wdq): Developing and validating a comprehensive measure for assessing job design and the nature of work. Journal of Applied Psychology, 91, 1321-1339. doi: 10.1037/00219010.91.6.1321

Motowildo, S. J., Borman, W. C., \& Schmit, M. J. (1997). A theory of individual differences in task and contextual performance. Human Performance, 10, 71-83. doi: 10.1207/s15327043hup1002_1

Nencini, A., Romaioli, D., \& Meneghini, A. M. (2016). Volunteer motivation and organizational climate: Factors that promote satisfaction and sustained volunteerism 
in npos. VOLUNTAS: International Journal of Voluntary and Nonprofit Organizations, 27, 618-639. doi: 10.1007/s11266-015-9593-Z

Neufeind, M., Güntert, S. T., \& Wehner, T. (2013). The impact of job design on event volunteers' future engagement: Insights from the european football championship 2008. European Sport Management Quarterly, 13, 537-556.

Newton, C., Becker, K., \& Bell, S. (2014). Learning and development opportunities as a tool for the retention of volunteers: A motivational perspective. Human Resource Management Journal, 24, 514-530. doi: 10.1111/1748-8583.12040

Newton, C. J., \& Mazur, A. K. (2016). Value congruence and job-related attitudes in a nonprofit organization: A competing values approach. International Journal of Human Resource Management, 27, in press. doi: 10.1080/095851192.2015.1053962

Nichols, G., \& Ojala, E. (2009). Understanding the management of sports events volunteers through psychological contract theory. VOLUNTAS: International Journal of Voluntary and Nonprofit Organizations, 20, 369-387.

Nichols, G., \& Ralston, R. (2012). The rewards of individual engagement in volunteering: A missing dimension of the big society. Environment and Planning A, 44, 2974-2987. doi: 10.1068/a45136

O'Connor, P. (1997). Working with and recruiting volunteers as part of a fundraising strategy. International Journal of Nonprofit and Voluntary Sector Marketing, 2, 353-362. doi: 10.1002/nvsm.6090020408

O'Toole, M., \& Grey, C. (2016). Beyond choice: 'Thick' volunteering and the case of the royal national lifeboat institution. Human Relations, 69, 85-109. doi: $10.1177 / 0018726715580156$

Okun, M. A. (1994). The relation between motives for organizational volunteering and frequency of volunteering by elders. Journal of Applied Gerontology, 13, 115-126. doi: $10.1177 / 073346489401300201$

Okun, M. A., \& Schultz, A. (2003). Age and motives for volunteering: Testing hypotheses derived from socioemotional selectivity theory. Psychology and aging, 18, 231-239.

Omoto, A. M., \& Snyder, M. (1995). Sustained helping without obligation: Motivation, longevity of service, and perceived attitude change among aids volunteers. Journal of Personality and Socia Psychology, 68, 671-686.

Omoto, A. M., Snyder, M., \& Martino, S. C. (2000). Volunteerism and the life course: Investigating age-related agendas for action. Basic and Applied Social Psychology, 22, 181-197. doi: 10.1207/S15324834BASP2203_6

Oostlander, J., Güntert, S. T., \& Wehner, T. (2014). Linking autonomy-supportive leadership to volunteer satisfaction: A self-determination theory perspective. VOLUNTAS: International Journal of Voluntary and Nonprofit Organizations, 25, 1368-1387.

Organ, D. W. (1997). Organizational citizenship behavior: It's construct clean-up time. Human Performance, 10, 85-97.

Paauwe, J. (2009). Hrm and performance: Achievements, methodological issues and prospects. Journal of Management Studies, 46, 129-142. doi: 10.1111/j.14676486.2008.00809.x

Paauwe, J., \& Boselie, P. (2003). Challenging 'strategic hrm' and the relevance of the institutional setting. Human Resource Management Journal, 13, 56-70.

Pearce, J. L. (1983). Job attitude and motivation differences between volunteers and employees from comparable organizations. Journal of Applied Psychology, 68, 646652.

Penner, L. A. (2002). Dispositional and organizational influences on sustained volunteerism: An interactionist perspective. Journal of Social Issues, 58, 447-467. doi: $10.1111 / 1540-4560.00270$ 
Penner, L. A., \& Finkelstein, M. A. (1998). Dispositional and structural determinants of volunteerism. Journal of Personality and Social Psychology, 74, 525-537. doi: 10.1037/0022-3514.74.2.525

Perry, J. L. (1996). Measuring public service motivation: An assessment of construct reliability and validity. Journal of Public Administration Research and Theory, 6, 522.

Phillips, L. C., \& Phillips, M. H. (2010). Volunteer motivation and reward preference: An empirical study of volunteerism in a large, not-for-profit organization. SAM Advanced Management Journal, 75, 12-39.

Phillips, L. C., \& Phillips, M. H. (2011). Altruism, egoism, or something else: Rewarding volunteers effectively and affordably. Southern Business Review, 36, 23-35.

Plummer, C. A., Ai, A. L., Lemieux, C. M., Richardson, R., Dey, S., Taylor, P., . . Kim, H.J. (2008). Volunteerism among social work students during hurricanes katrina and rita. Journal of Social Service Research, 34, 55-71. doi: 10.1080/01488370802086328

Pundt, L. M., Wöhrmann, A. M., Deller, J., \& Shultz, K. S. (2015). Differential predictors of post-retirement life and work satisfaction. Journal of Managerial Psychology, 30, 216.

Purcell, J., Kinnie, N., Hutchinson, S., Rayton, B., \& Swart, J. (2003). Understaning the people and performance link: Unlocking the black box. London: CIPD.

Randle, M., \& Dolnicar, S. (2012). Attracting volunteers in highly multicultural societies: A marketing challenge. Journal of Nonprofit \& Public Sector Marketing, 24, 351-369. doi: 10.1080/10495142.2012.733668

Reeder, G. D., Davison, D. M., Gipson, K. L., \& Hesson-McInnis, M. S. (2001). Identifying the motivations of african american volunteers working to prevent hiv/aids. AIDS Education and Prevention, 13, 343-354. doi: 10.1521/aeap.13.4.343.21425

Restivo, M., \& van de Rijt, A. (2014). No praise without effort: Experimental evidence on how rewards affect wikipedia's contributor community. Information, Communication \& Society, 17, 451-462.

Ridder, H.-G., \& McCandless, A. (2010). Influences on the architecture of human resource management in nonprofit organizations: An analytical framework. Nonprofit and Voluntary Sector Quarterly, 39, 124-141. doi: 10.1177/0899764008328182

Rodell, J. B., Breitsohl, H., Schröder, M., \& Keating, D. J. (2016). Employee volunteering: A review and framework for future research. Journal of Management, 42, 55-84. doi: 10.1177/0149206315614374

Rogers, S. E., Jiang, K., Rogers, C. M., \& Intindola, M. (2016). Strategic human resource management of volunteers and the link to hospital patient satisfaction. Nonprofit and Voluntary Sector Quarterly, 45, 409-424. doi: 10.1177/0899764015596434

Rogers, S. E., Rogers, C. M., \& Boyd, K. D. (2013). Challenges and opportunities in healthcare volunteer management: Insights from volunteer administrators. Hospital Topics, 91, 43-51. doi: 10.1080/00185868.2013.806012

Ryan, R., \& Deci, E. (2000). Self-determination theory and the facilitation of intrinsic motivation, social development, and well-being. American Psychologist, 55, 68-78. doi: 10.1037/0003-066X.55.1.68

Saksida, T., Alfes, K., \& Shantz, A. (2016). Volunteer role mastery and commitment: Can hrm make a difference? The International Journal of Human Resource Management, 1-23. doi: 10.1080/09585192.2015.1126335

Salamon, L. M., Sokolowski, S. W., \& Anheier, H. K. (2000). Social origins of civil society: An overview: Johns Hopkins Center for Civil Society Studies Baltimore, MD.

Schlesinger, T., Klenk, C., \& Nagel, S. (2015). How do sport clubs recruit volunteers? Analyzing and developing a typology of decision-making processes on recruiting 
volunteers in sport clubs. Sport Management Review, 18, 193-206. doi: http://dx.doi.org/10.1016/j.smr.2014.04.003

Schroer, J., \& Hertel, G. (2009). Voluntary engagement in an open web-based encyclopedia: Wikipedians and why they do it. Media Psychology, 12, 96-120.

Shantz, A., Arevshatian, L., Alfes, K., \& Bailey, C. (2016). The effect of hrm attributions on emotional exhaustion and the mediating roles of job involvement and work overload. Human Resource Management Journal, 26, 172-191. doi: 10.1111/1748-8583.12096

Shantz, A., Saksida, T., \& Alfes, K. (2014). Dedicating time to volunteering: Values, engagement, and commitment to beneficiaries. Applied Psychology. An International Review, 63, 671-697. doi: 10.1111/apps.12010

Skoglund, A. G. (2006). Do not forget about your volunteers: A qualitative analysis of factors influencing volunteer turnover. Health \& Social Work, 31, 217-220.

Snyder, M., \& Omoto, A. M. (2008). Volunteerism: Social issues perspectives and social policy implications. Social Issues and Policy Review, 2, 1-36. doi: 10.1111/j.17512409.2008.00009.x

Stirling, C., Kilpatrick, S., \& Orpin, P. (2011). A psychological contract perspective to the link between non-profit organizations' management practices and volunteer sustainability. Human Resource Development International, 14, 321-336.

Stukas, A. A., Hoye, R., Nicholson, M., Brown, K. M., \& Aisbett, L. (2016a). Motivations to volunteer and their associations with volunteers' well-being. Nonprofit and Voluntary Sector Quarterly, 45, 112-132. doi: 10.1177/0899764014561122

Stukas, A. A., Snyder, M., \& Clary, E. G. (2016b). Understanding and encouraging volunteerism and community involvement. Journal of Social Psychology, 156, 243255. doi: $10.1080 / 00224545.2016 .1153328$

Stukas, A. A., Worth, K. A., Clary, E. G., \& Snyder, M. (2009). The matching of motivations to affordances in the volunteer environment: An index for assessing the impact of multiple matches on volunteer outcomes. Nonprofit and Voluntary Sector Quarterly, 38, 5-28. doi: 10.1177/0899764008314810

Subramony, M. (2009). A meta-analytic investigation of the relationship between hrm bundles and firm performance. Human Resource Management, 48, 745-768. doi: 10.1002/hrm.20315

Sundeen, R. A., Raskoff, S. A., \& Garcia, M. C. (2007). Differences in perceived barriers to volunteering to formal organizations: Lack of time versus lack of interest. Nonprofit Management and Leadership, 17, 279-300. doi: 10.1002/nml.150

Tang, F., Morrow-Howell, N., \& Hong, S. (2009). Institutional facilitation in sustained volunteering among older adult volunteers. Social Work Research, 33, 172-182. doi: $10.1093 / \mathrm{swr} / 33.3 .172$

Tidwell, M. V. (2005). A social identity model of prosocial behaviors within nonprofit organizations. Nonprofit Management and Leadership, 15, 449-467. doi: $10.1002 / \mathrm{nml} .82$

Valéau, P., Mignonac, K., Vandenberghe, C., \& Gatignou Turnau, A.-L. (2013). A study of the relationships between volunteers' commitments to organizations and beneficiaries and turnover intentions. Canadian Journal of Behavioural Science, 45, 85-95. doi: $10.1037 / \mathrm{a} 0027620$

Valeau, P., Willems, J., \& Parak, H. (2016). The effect of attitudianl and behavioral commitment on the internal assessment of organizational effectiveness: A multilevel analysis. VOLUNTAS: International Journal of Voluntary and Nonprofit Organizations, Doi: 10.1007/s11266-016-9703-6.

Van De Voorde, K., Paauwe, J., \& Van Veldhoven, M. (2012). Employee well-being and the hrm-organizational performance relationship: A review of quantitative studies. 
International Journal of Management Reviews, 14, 391-407. doi: 10.1111/j.14682370.2011.00322.x

Vantilborgh, T., Bidee, J., Pepermans, R., Willems, J., Huybrechts, G., \& Jegers, M. (2012). Volunteers' psychological contracts: Extending traditional views. Nonprofit and Voluntary Sector Quarterly, 41, 1072-1091. doi: 10.1177/0899764011427598

Waikayi, L., Fearon, C., Morris, L., \& McLaughlin, H. (2012). Volunteer management: An exploratory case study within the british red cross. Management Decision, 50, 349367. doi: doi:10.1108/00251741211216188

Waters, R. D., \& Bortree, D. S. (2012). Improving volunteer retention efforts in public library systems: How communication and inclusion impact female and male volunteers differently. International Journal of Nonprofit \& Voluntary Sector Marketing, 17, 92107. doi: $10.1002 /$ nvsm.438

Whithear, R. (1999). Charity shop volunteers: A case for 'tender loving care'. International Journal of Nonprofit \& Voluntary Sector Marketing, 4, 107-120. doi: 10.1002/nvsm.62

Wilson, A., \& Pimm, G. (1996). The tyranny of the volunteer: The care and feeding of voluntary workforces. Management Decision, 34, 24-40. doi: doi:10.1108/00251749610115134

Wilson, J. (2000). Volunteering. Annual Review of Sociology, 26, 215-240. doi: doi:10.1146/annurev.soc.26.1.215

Wilson, J. (2012). Volunteerism research: A review essay. Nonprofit and Voluntary Sector Quarterly, 41, 176-212. doi: 10.1177/0899764011434558

Wright, P. M., \& Boswell, W. R. (2002). Desegregating hrm: A review and synthesis of micro and macro human resource management research. Journal of Management, 28, 247-276. doi: 10.1177/014920630202800302

Wrzesniewski, A., \& Dutton, J. E. (2001). Crafting a job: Revisioning employees as active crafters of their work. Academy of Management Review, 26, 179-201. doi: 10.5465/amr.2001.4378011

Yagi, R. (2006). Training and supporting the 'volunteers': Revisiting total literacy campaigns in india. International Journal of Educational Development, 26, 67-87. doi: http://dx.doi.org/10.1016/j.ijedudev.2005.07.013

Zappa, P., \& Zavarrone, E. (2010). Social interaction and volunteer satisfaction: An exploratory study in primary healthcare. International Review of Economics, 57, 215231. doi: 10.1007/s12232-010-0095-4 